International Review of Research in Open and Distributed Learning Volume 16, Number 2

April - 2015

\title{
Influencing Factors in OER Usage of Adult Learners in Korea
}

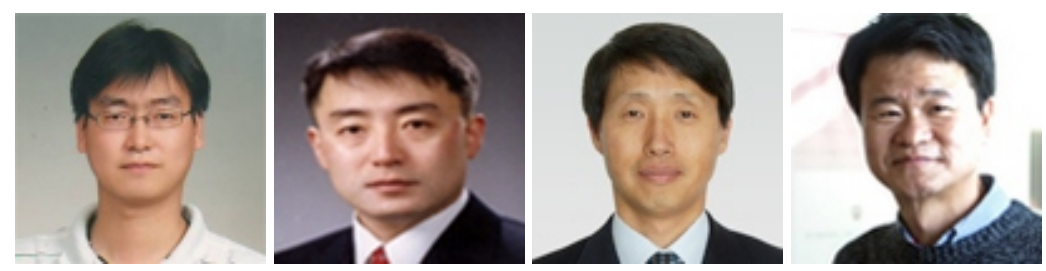

Byoung Wook Kim ${ }^{1}$, Won Gyu Lee ${ }^{1}$, Byeong Rae Lee ${ }^{2}$, and Jin Gon Shon ${ }^{2}$ ${ }^{1}$ Korea University, Korea, ${ }^{2}$ Korea National Open University, Korea

\begin{abstract}
Open Educational Resources (OER) is terminology that refers to educational resources (content and software) distributed through the Internet, free of charge and freely accessible, expanding learning opportunities for adult learners. This terminology first appeared around 2002, although its roots can be traced to the open architecture of the Internet. Until recently, OER development has focused more on quantity of contents rather than quality. In this study, we have examined the factors influencing the learning intention of adult learners in the OER context. Based on the relevant literature, we have identified a number of factors influencing a learner's intention to use e-learning content. We have also developed a questionnaire for conducting a survey on such influencing factors. The survey results show that ease of use and relation to immediate workplace needs affect the intention of adult learners in using OER. The findings of this study can inform those developing and designing a learning environment that employs OER while also providing general guidance for developers and educators on how to design OER content.
\end{abstract}

Keywords: Open educational resources; adult learners; e-learning; regression analysis 


\section{Introduction}

The concept of lifelong education can be seen to involve openness and flexibility, in contrast to school education (Knapper \& Cropley, 2000). Therefore, it is arguable that promoting lifelong education is consistent with bringing about an open learning society in which everyone can receive an education, regardless of when and where the need arises. Such a knowledge-based society requires changing the educational paradigm from closed school-based education to lifelong education (Aspin et al., 2001). The Organization for Economic Cooperation and Development (OECD, 1973) has suggested an educational system which enables adults to learn by avoiding the traditional educational paths as a strategy for lifelong education. Reorganization of the lifelong education system is reflected in the concept and vision of national educational policies (Kanwar et al., 2010). In recent years universities have changed their educational systems to be more open while also strengthening their role in providing lifelong education. Open Education Resources (OER) has also emerged as a key driver of change in the educational paradigm from school-centered education to lifelong education (Johnstone, 2005). OER promotes freely available educational resources for use, reuse, adaptation and sharing through the Internet (Wiley, 2007). OER can therefore make a contribution to expanding educational opportunities and developing a lifelong learning society because they freely provide content at higher educational levels.

Moreover, the benefits of OER also extend into promoting improvement in human intellectual capacity through the sharing of knowledge. Likewise, as the movement to embrace OER has grown the educational purpose has been expanded gradually in government, institutions of higher education, and among scholars with an internal and external interest, as it has received positive responses from these sectors (Friesen, 2009). Because OER has been playing an important role in lifelong education, a wide range of studies have been conducted to improve the quality of OER including its content, management, and services. However, studies investigating why adult learners continue to be satisfied when utilizing OER are relatively scant. Although there are many cases concerning innovative teaching and learning methods while employing technologies effectively, research focusing on the strategies to promote acceptance and use of direct users is still in its formative stages (Friesen, 2009).

Wood (2005) pointed out that learners who were successful in a traditional learning environment might not be successful in an online learning environment. This lack of success in online learning can be due to issues of student motivation, self-discipline, and learner characteristics. Evaluation of learner differences and how they impact on educational achievement is one factor in understanding the successful learning outcome in online learning environments. In other words, when using new learning methods or resources it is critical to consider learner characteristics and requirements rather than merely introducing and applying new technology to an educational environment.

This work is licensed under a Creative Commons Attribution 4.0 International License. 
Following on, it is especially important to consider learners' needs and requirements in an educational paradigm shifting from a supplier-centered educational environment to a consumercentered one. However, it is not uncommon to see educational stakeholders paying great attention to developing innovative teaching and learning methods for the effective utilization of technology while devoting less effort to promoting strategies for acceptance and use among direct users.

The belief that all learners can naturally use innovative technologies in an educational environment seems controversial (Oppenhimer, 2003). Furthermore, the application of new technology in education does not guarantee acceptance and use by learners (Kiraz \& Ozdemir, 2006). Therefore, OER, as an innovation in the development and delivery of online educational resources, requires systematic analysis in order to improve its effects for learners. Given this need, it is urgent that the deciding factors in adult learners' intentions to use OER be identified and thoroughly analyzed to determine those factors that have the influence on the use of OER.

Many researchers have examined which variables influence user acceptance of information technology and developed various models and theories to establish relationships among variables (Davis, 1989; Venkatesh et al., 2003). Among various models and theories, the Technology Acceptance Model (TAM) includes significant factors affecting the uses of technology, and has explanations concerning user acceptance and usage behavior (Davis, 1989; Venkatesh et al., 2003; Chin \& Gopal, 1995; Cheung et al., 2000; Al-Adwan et al., 2013). TAM has been adopted and extended by many researchers to examine usage of technology in their respective research areas. However, previous studies related to user intentions for the new information technologies based on Technology Acceptance Model (TAM) have targeted internet or mobile technology with an emphasis on learning effectiveness (Chin \& Gopal, 1995; Cheung et al., 2000; Al-Adwan et al., 2013). In many empirical studies employing TAM, the vast majority of participants were university students, and the usual variables were derived from the perspective of individual characteristics (e.g., gender, age, etc.) (Gefen \& Straub, 1997). Studies considering adult learners' characteristics have focused on e-learning in general rather than on OER specifically (Liao \& Liu, 2011).

The purpose of this study is to identify related factors of adults' learning in terms of their intention for using OER while addressing the relationship between those factors. More specifically, this paper examines the variables associated with adult learners that show significant effects on use of OER and studies the relationship between the variables and overall influence respectively. The variables used in this study are the components of the original TAM and factors on satisfaction with e-learning. An online survey was developed and used to collect data for this and was conducted with 1,158 adult learners. The regression analysis was employed to predict the factors associated with the OER's intended use. Results show that ease of use and relation to their jobs are key factors in the intention of adult learners to use OER.

This work is licensed under a Creative Commons Attribution 4.0 International License. 
The importance of the study lies in the fact that it is the first exploratory research to address the acceptance and adoption of OER by adult learners. The contribution of this study is manifested in developing OER contents which could be used in the field of lifelong education to provide effective strategies in the promotion of OER use for adult learners.

\section{Background}

\section{OER and Lifelong Education}

OER have been defined as "digitised materials offered freely and openly for educators, students and self-learners to use and re-use for teaching, learning and research" (Hylén, 2006). The term OER was first introduced in a UNESCO Forum in 2002 as part of Education For All, with the intention of describing the distribution of educational resources free of charge through the Internet (Wiley, 2007). One of the related campaigns was MIT's OpenCourseware (OCW) project, which was initially a collection of free college lectures provided online in 2001. After that, several higher education institutions, including Utah State University and Carnegie Mellon, started to participate in the similar programs. Recently, OER has gradually extended its range in keeping with the growth of e-learning and Web 2.0 while taking into account a learner-centered paradigm and strategies shared by practitioners and scholars.

When the International Council for Distance Education's Standing Conference of Presidents (ICDESCOP) was held to address the subject of OER as an instrument for achieving Education For All in 2007, it reflected the promising characteristics of OER, which was regarded as a method to realize the humanistic ideology of lifelong education. And the fact that about half of participants in MIT OCW are lifelong learners shows that OER is being well utilized for lifelong education. The OECD report (2007) suggested that educational systems for the purpose of open learning should be made available. Furthermore, it was expected that OER could enlarge access to higher education to all citizens as well as to traditional students, which would be an efficient method to promote lifelong education for the government and individuals.

According to Moore and Kearsley (1996), "most distance education students are adults between the ages of 25 and 50. Consequently the more one understands the nature of adult learning, the better one can understand the nature of distance learning" (p. 153). Generally, adult learners are different from traditional college students (Cercone, 2008). Many adult learners have the responsibilities of a job and family that can interfere with the learning process (Kazis, 2007). Therefore, adult learners have many reasons why they cannot continue learning because of lack of time, money, and ability, which are often mentioned as the factors that hinder adults' participation in learning.

This work is licensed under a Creative Commons Attribution 4.0 International License. 
Previous studies investigated and revealed the factors that lead learners to participate in and drop out of lifelong education. These are studies analyzing those persons who drop out (Rovai, 2003) and those who complete courses, focusing on their individual backgrounds by analyzing quantitative participation patterns in online university courses (Nistor \& Neubauer, 2010). With the goal of finding helpful strategies for students to continue learning, these studies advanced a causal explanation as to why they drop out.

The studies on continued participation of adult learners suggest a relationship between learners' background characteristics and continued participation (Ivankova \& Stick, 2007). The background factors include gender, age, educational background, and income. In addition, psychological factors-like confidence in practicing successful learning, participation motives, and psychological satisfaction through psychological experiences and educational institution factorswere reported as having a significant effect on the process of deciding to continue participation. It can be difficult for adult learners to have time to study when having to combine work, learning, and leisure. Thus, continued learning occurs in the context of various complex factors. However, existing studies cannot explain in detail how each factor results in dropouts or continued learning. Furthermore, as the focus of previous studies of these factors is more about dropouts who seek to continue learning, an in-depth understanding of how to address this phenomenon in a rigorous way is required.

\section{Acceptance Factor of OER users}

Developed from Fishbein and Ajzen's (1975) Theory of Reasoned Action (TRA), the basic model of Technology Acceptance Model (TAM) was first suggested by Davis (1989) when trying to explain behaviors of individuals adopting certain information technologies. The reasonable action theory explained human behaviors by understanding the causal relationship between several variables such as belief, attitudes, intent, and behaviors (Kwon \& Chidambaram, 2000). As for the basic assumption of TRA, a specific individual behavior is employed if it is believed to accomplish positive results (Compeau \& Higgins, 1995). According to TRA, actual behaviors are influenced by behavioral intent, which is indicated by attitudes and subjective norms. The attitudes refer to a belief in the expected outcomes of such behaviors. The subjective norms refer to a belief in how other people think of the behaviors (Ajzen \& Fishbein, 1980).

TAM is a theory widely used to understand how users accept and use a new information technology and it has been studied in various fields by several researchers (Moon \& Kim, 2001). Davis (1989, p. 320) defined 'perceived ease of use' as "the degree to which a person believes that using a particular system would be free of effort," and 'perceived usefulness' as "the degree to which a person believes that using a particular system would enhance his or her job performance." TAM posited the concrete concept of 'perceived ease of use' and 'perceived usefulness' as two influencing factors on which an individual decides whether or not to use a new technology.

This work is licensed under a Creative Commons Attribution 4.0 International License. 
The studies which applied existing models to the acceptance of technologies have been done usually by examining individual behaviors in the use of online social business networks (Moeser et al., 2013) and internet shopping in web (Moon \& Kim, 2001) or by predicting consumers' acceptance of new technologies in the points of sale (Pantano \& Pietro, 2012).

The many studies of TAM in educational fields have been conducted to identify hindrance factors of technology acceptance as well as promotion factors. In the current studies, the factors that have an effect on the acceptance or use of technologies were extracted and summarized in e-learning or m-learning (Muilenburg \& Berge, 2005; Iqbal \& Qureshi, 2012; Escobar-Rodriguez \& MongeLozano, 2012). They were empirically utilized in previous research done by professors, teachers, and students in educational fields. Accessibility, compatibility, complexity, convenience of use, prior experience and knowledge about computers, relative advantages, subjective norms, and selfefficacy were drawn upon.

The studies identified the factors in the utilization of information technologies targeting ordinary persons and are examined below. When analyzing the effect of computer self-efficacy on technical utilization at the workplace, Stone and Henry (2003) found that impact of computer experiences and system utilization on organizational commitment is related to computer self-efficacy, while the expectation of the result and convenience of computer use have an effect on organizational commitment because of expectations regarding the result. Cheung et al. (2000) argued that the complexity of the Internet affects levels of the Internet usage and actual use and that the social factors seem to have a direct effect on use levels of the Internet.

\section{Research Design}

OER can be understood as supporting freely accessible e-learning delivered through the Internet. Therefore, an analysis of previous studies was done to determine the factors related to the intention of using e-learning and, thus, OER. Based on previous research, a theoretical model was developed. We transformed the factors of the intention to use e-learning to fit OER. Finally, we adopted six factors: (1) perceived ease of use (PE), (2) perceived usefulness (PU), (3) attitude (AT), (4) subjective norm (SN), (5) self-efficacy (SE), and (6) job-fit (JF). In accordance with the

research objective and consistent with related researches, this study addresses the following hypotheses:

H1: PE will have a significant influence on adult learners' intention to use OER.

H2: PU will have a significant influence on adult learners' intention to use OER.

H3: AT will have a significant influence on adult learners' intention to use OER.

H4: SN will have a significant influence on adult learners' intention to use OER.

This work is licensed under a Creative Commons Attribution 4.0 International License. 
H5: SE will have a significant influence on adult learners' intention to use OER.

H6: J F will have a significant influence on adult learners' intention to use OER.

These hypotheses are presented in the research model in Figure 1.

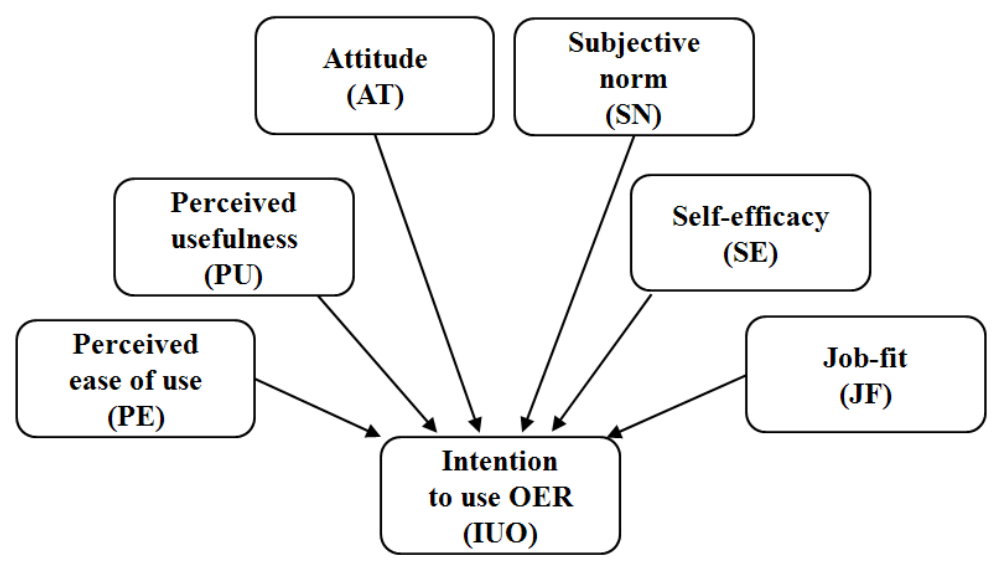

Figure 1. Graphical sketch of the research model.

\section{Method}

\section{Participants}

We conducted a survey to determine the intention to use OER. The population in the study consists of university students at the Korea National Open University (KNOU). An online survey was developed and used to collect the data then sent by e-mail to all students. The survey was conducted from August 27, 2012 to September 16, 2012. A total of 1,158 (N=1,158) students responded to the survey. We administered the survey for the students of KNOU, as the institution provides all of its classes through remote media, such as TV lecture and e-learning. We ensured that the students were familiar with using educational resources on the Internet for learning. 
Table 1

Demographic Information of the Participants

\begin{tabular}{cccc}
\hline & & Number $(\mathrm{N})$ & Percent (\%) \\
\hline \multirow{2}{*}{ Gender } & Male & 397 & 65.7 \\
& Female & 761 & 34.3 \\
\hline \multirow{3}{*}{ Age } & $18 \sim 29$ & 254 & 21.9 \\
& $30 \sim 39$ & 339 & 29.3 \\
& $40 \sim 49$ & 359 & 31.0 \\
& $50 \sim 59$ & 169 & 14.6 \\
& $60 \sim 71$ & 37 & 3.2 \\
\hline
\end{tabular}

The participants were 39.6 years old on average (std. $=11.0$, $\max =71$, $\min =18$ ), older than most university students. Therefore, we treated the participants in this study as adult learners. The demographic information of the participants is given in Table 1.

\section{Data Collection Tools}

The survey was developed based on the objective of the study and a previous literature review. The survey was composed of two parts: demographic information of the participants and their responses regarding the six factors, and one dependent variable - the intention to use OER (IUO).

$\mathrm{PE}$ and PU consisted of three items each of which focused on measuring the degree to which a person believes that using OER would enhance academic performance and would be free of effort (Davis, 1989; Venkatesh et al., 2003). SN consisted of three items focusing on an individual's perception of whether people important to the individual think the behavior should or should not be performed (Ajzen, 1991). AT included three items and focused on the individual's positive or negative feelings about using OER (Davis et al. 1989, Fishbein and Ajzen, 1975). SE consisted of two items and focused on the belief in one's ability to use OER to accomplish a particular job or task (Venkatesh et al., 2003). J F consisted of four items and focused on the measurement of the extent to which an individual believes that using OER could enhance his/her job performance (Thompson et al. 1991). IUO was measured using three items, which mainly focused on the participant's intention to use OER. All items were measured on 5-point Likert-type scales, from 1 $=$ strongly disagree to $5=$ strongly agree.

Content validity of the survey was established by three educational technology experts. Data reliability for each factor was checked by means of Cronbach's alpha, which was found to be as follows: $\mathrm{PE}=.864, \mathrm{PU}=.884, \mathrm{AT}=.836, \mathrm{SN}=.775, \mathrm{SE}=.802$, $\mathrm{JF}=.927$ and $\mathrm{BI}=.802$. Since all of these factors are greater than .70 , they fall in an acceptable range. 


\section{Results}

\section{Descriptive Statistics}

The descriptive statistics for all the items used in this study are given in Table 2. All means of items are above 3.62. The standard deviations range from 0.68 to 1.06 , indicating a narrow distribution around the mean.

Table 2

Descriptive Statistics of Factors Affecting Intent to Use OER

\begin{tabular}{|c|c|c|c|}
\hline Factor & Measurement instrument & Mean & $\mathrm{SD}$ \\
\hline \multirow{3}{*}{$\begin{array}{l}\text { Perceived } \\
\text { ease of use } \\
\quad(\mathrm{PE})\end{array}$} & I find OER on the Internet easy to use. & 3.74 & 1.01 \\
\hline & It is easy to become skillful at using OER. & 3.87 & 0.95 \\
\hline & It is easy to access information in OER. & 3.62 & 0.98 \\
\hline \multirow{3}{*}{$\begin{array}{l}\text { Perceived } \\
\text { Usefulness } \\
\text { (PU) }\end{array}$} & Use of OER will improve academic productivity. & 3.87 & 0.80 \\
\hline & Use of OER will increase my learning performance. & 3.81 & 0.79 \\
\hline & $\begin{array}{l}\text { Use of OER enabled me to accomplish tasks more } \\
\text { quickly. }\end{array}$ & 3.64 & 0.79 \\
\hline \multirow{3}{*}{ Attitude (AT) } & I am positive toward OER. & 4.21 & 0.68 \\
\hline & Studying through OER is a good idea. & 4.08 & 0.73 \\
\hline & Studying through OER is a wise idea. & 4.14 & 0.70 \\
\hline \multirow{3}{*}{$\begin{array}{l}\text { Subjective } \\
\text { norm } \\
\text { (SN) }\end{array}$} & $\begin{array}{l}\text { I like using OER based on the similarity between my } \\
\text { values and society's values regarding its use. }\end{array}$ & 4.07 & 0.68 \\
\hline & What OER stands for is important for me as a learner. & 3.94 & 0.72 \\
\hline & I think that my peers often use OER. & 4.00 & 0.70 \\
\hline \multirow{4}{*}{$\begin{array}{l}\text { Job-fit } \\
\text { (JF) }\end{array}$} & OER will have an effect my job performance. & 3.70 & 0.95 \\
\hline & $\begin{array}{l}\text { OER can decrease the time needed for important job } \\
\text { responsibilities. }\end{array}$ & 3.67 & 1.06 \\
\hline & $\begin{array}{l}\text { OER can increase the effectiveness of performing job } \\
\text { tasks. }\end{array}$ & 3.87 & 0.94 \\
\hline & $\begin{array}{l}\text { OER can increase the quantity of output for the same } \\
\text { amount of effort. }\end{array}$ & 3.76 & 1.00 \\
\hline \multirow{2}{*}{$\begin{array}{c}\text { Self-efficacy } \\
\text { (SE) }\end{array}$} & I have the necessary skills for using OER. & 3.64 & 0.91 \\
\hline & I feel confident in finding information in OER. & 3.95 & 0.85 \\
\hline \multirow{3}{*}{$\begin{array}{c}\text { Intention to } \\
\text { use OER } \\
\text { (IUO) }\end{array}$} & I intend to check announcements from OER frequently. & 3.83 & 0.82 \\
\hline & I will always try to use OER in my daily life. & 3.93 & 0.72 \\
\hline & I intend to continue using OER in the future. & 4.01 & 0.70 \\
\hline
\end{tabular}

Scale: $1=$ strongly disagree $\sim 5=$ strongly agree 


\section{Hypotheses Testing}

This study employed multiple linear regression to confirm factors affecting the intention to use OER. Table 3 shows the results of the hypotheses tests by confirming the presence of a statistically significant relationship in the predicted direction of the proposed research model. Overall, 2 out of 6 hypotheses were supported by data.

Table 3

Multiple Regression Result: T-Value, Significance, Tolerance

\begin{tabular}{cllc}
\hline Factors & T-value & Significance & Tolerance \\
\hline PE & 4.423 & $.000^{* *}$ & .555 \\
PU & -.761 & .446 & .519 \\
AT & .185 & .853 & .501 \\
SN & -.714 & .476 & .488 \\
SE & -.288 & .773 & .792 \\
JF & 9.667 & $.000^{* *}$ & .639 \\
\hline
\end{tabular}

$* * . \mathrm{p}<0.001$

The t-value for the effect of PE influencing the intention to use OER is 4.423 ( $p<001)$, and thus hypothesis 1 is confirmed. Also, the t-value for the effect of J F influencing on the intention to use OER is 9.667 ( $p<001)$, and thus confirming hypothesis 6. The result of the experiment shows that $\mathrm{PE}$ and J F have a positive effect on adult learners' intention to use OER is statistically significant.

The F-value for the regression model is $23.270(\mathrm{p}=.000)$ and $\mathrm{R}^{2}$ for the regression equation is .206 (20.6\%). Other hypotheses were rejected because the t-value is greater than -1.96 and less than 1.96 ( $p>0.001$ ). The value of each tolerance is more than 0.1 , and thus a multicollinearity problem is not found. 
Table 4

Results of Hypotheses Testing

\begin{tabular}{rlc}
\hline \multicolumn{1}{c}{ Hypothesis } & \multicolumn{1}{c}{ Supported? } \\
\hline H1 & $\begin{array}{l}\text { PE will have a significant influence on adult learners' intention to } \\
\text { use OER }\end{array}$ & Yes \\
H2 $\begin{array}{l}\text { PU will have a significant influence on adult learners' intention to } \\
\text { use OER }\end{array}$ & No \\
H3 $\begin{array}{l}\text { AT will have a significant influence on adult learners' intention to } \\
\text { use OER }\end{array}$ & No \\
H4 $\begin{array}{l}\text { SN will have a significant influence on adult learners' intention to } \\
\text { use OER }\end{array}$ & No \\
H5 $\begin{array}{l}\text { SE will have a significant influence on adult learners' intention to } \\
\text { use OER } \\
\text { JF will have a significant influence on adult learners' intention to } \\
\text { use OER }\end{array}$ & No \\
\hline
\end{tabular}

\section{Discussion and Conclusion}

The goal of this study was to analyze the factors that affect adult learners' intentions to use OER in models of the acceptance of information technologies. In conducting the analysis, the six factors in the models of the acceptance of information technologies that have an effect on the intention to use OER were selected and the effect of these factors on intention to use OER was examined through regression analysis. One of the interesting results of this study is that both PE (Perceived ease of use) and J F (J ob-fit) play an important, positive role in affecting the behavioral intention to use OER.

The results of this study by factor are discussed as follows. The studies on TAM models to explain the intent to use the existing e-learning reported that e-learning's self-efficacy (Park, 2009), subjective norms (Cheung, Chang \& Lai, 2000), attitudes (Ajzen \& Fishbein, 1980), and perceived usefulness (Venkatesh et al., 2003) are the influencing factors. However, the current study reports that PE and JF have significant effects on intention to use OER. PE was found to be the one factor from previous studies that has an effect on technical use (Yildirim, 2000) in educational fields. Because the average age of adult learners is greater than that of most university students, their ability to utilize computers cannot help being lower. Thus, even though useful and necessary information is provided through OER, intention to use cannot help being lower if a computer is not easy to use. The reason that OER use is important for adult learners can be found in the answer to the questions about plans to utilize it.

This work is licensed under a Creative Commons Attribution 4.0 International License. 
"I think that OER is difficult for seniors to use when I utilized it as a worker. The more data there is, the more complicated the sites are. If the data is divided into simple categories only the data that you want can be accessed by strengthening the search capability and the environment to facilitate finding it, then I think that people who are not good at computers can easily access OER." (Participant, personal communication, September 7, 2012)

The many studies on the intention to use e-learning have found that PU (Perceived usefulness) is the one factor that has an effect on use intent. However, this study has found that PU has no effect on intention to use. This is because the participants in this study were adult learners who take university courses through e-learning, not general adult learners. In this study, PU focuses on learning utility, and all participants received sufficient content related to learning through elearning from university.

However, learning using OER is not compulsory for adult learners and so it is difficult to concentrate on the Internet for a long time. Therefore, the majority of adult learners were found to prefer OER content that they are interested in and which they could easily understand, such as special lectures by experts or a key issue in a particular field rather than the contents that are directly related to learning.

The effect of JF on intent to use OER was found to come from the characteristics of most of those adult learners who have jobs. This is because there are many cases in which OER are selectively carried out by a necessity or requirement to practice their studies as an educational method in assisting with primary learning rather than as essential educational methods which are utilized in regular educational courses until now. And it is a result which comes from the educational environment of the adult learners where it is difficult to find time to study when combining work, learning, and leisure.

"OER users are usually busy workers who cannot acquire knowledge offline. The content related to studies can be learned through e-learning. Studies need continuity. I hope that OER will provide the contents of special lecture types which can improve business capabilities in the workplace." (Participant, personal communication, September 7, 2012)

If the existing OER policies focused on provision and extension of the learning opportunities, policies that extend learning opportunities are connected to actual utilization should be promoted now. To do this, service strategies that can increase convenience of use and strategies to develop content that better connects users and their jobs should be established to promote acceptance and

This work is licensed under a Creative Commons Attribution 4.0 International License. 
the intention to use OER. Based on the above research results, the following proposals are suggested.

First, web sites which provide OER services should be made available through an interface that is simple and can increase learning efficiency to the maximum. Provision of the most convenient search function should enable learners to find OER that they want as soon as possible. Services that OER service operators can actively help learners including one-on-one counseling and Q\&A should be provided after taking into consideration adult learner characteristics. In other words, learning through OER should focus on providing those services that include functions to manage learning, or counseling to enable learners to manage their learning smoothly through OER rather than by focusing on providing high quality content.

Second, OER should provide contents that are directly related to adult learner jobs. OER contents that enable users to understand each field's trends or extend knowledge related to various jobs should be provided. Information summarized by experts from difficult subjects or content that is easy and simple for ordinary persons should be provided rather than knowledge acquired over a long period of time through fixed educational courses such as the general learning content in elearning.

Third, concrete strategies to vitalize OER and promotional strategies to meet research subjects' situations should be developed by grouping research subjects according to their demographic characteristics (e.g., gender, major, and age) or by verifying the research models through correlating the intention to use OER with influencing factors targeting elementary, middle, and high school students, but not those of adult learners. Extension of models that multilaterally approach intention to use OER as well as follow-up studies are needed to categorize the factors of social environment and individual characteristics that are of greatest consequence.

This work is licensed under a Creative Commons Attribution 4.0 International License. 


\section{References}

Ajzen, I., \& Fishbein, M. (1980). Understanding attitudes and predicting social behavior. Englewood Cliffs, NJ : Prentice-Hall.

Ajzen, I. (1991). The theory of planned behavior. Organizational Behavior and Human Decision Processes, 50(2), 179-211.

Al-Adwan, A., Al- Adwan, A., \& Smedley, J . (2013). Exploring students acceptance of e-learning using Technology Acceptance Model in J ordanian universities. International J ournal of Education and Development using Information and Communication Technology, 9(2), 4-18.

Aspin, D., Chapman, J ., Hatton, M., \& Sawano, Y. (2001). Lifelong learning: Small adjustment or paradigm shift? International handbook of lifelong learning, 183-198. doi: 10.1007/97894-010-0916-4_ 12

Cercone, K. (2008). Characteristics of adult learners with implications for online learning design. AACE J ournal, 16(2), 137-159.

Cheung, W., Chang, M. K., \&Lai, V. S. (2000). Prediction of internet and world wide web usage at work: A test of an extended triandis model. Decision Support Systems, 30(1), 83-100.

Compeau, D. R., \& Higgins, C. A. (1995). Computer self-efficacy: Development of a measure and initial test. MIS Quarterly, 19(2), 189-211.

Cross, K. P. (1981). Adults as learners: Increasing participation and facilitating learning. San Francisco: J osse Bass Publishers.

Davis, F. D. (1989). Perceived usefulness, perceived ease of use, and user acceptance of information technology. MIS Quarterly, 13(3), 319-340.

Davis, F. D., Bagozzi, R. P., \&Warshaw, P. R. (1989). user acceptance of computer technology: A comparison of two theoretical models. Management Science, 35(9), 982-1003.

Davis, F. D. (1993). User acceptance of information technology: System characteristics, user perceptions and behavioral impacts. International J ournal of Man-Machine Studies, 38(3), 475-487.

Escobar-Rodriguez, T., \& Monge-Lozano, P. (2012). The acceptance of Moodle technology by business administration students. Computers \& Education, 58(4), 1085- 1093.

Fishbein, M., \&Ajzen, I. (1975). Belief, attitude, intention and behavior: An introduction to theory and research. Addison-Wesley, Reading, MA.

This work is licensed under a $\underline{\text { Creative Commons Attribution } 4.0 \text { International License. }}$ 
Friesen, N. (2009). Open educational resources: New possibilities for change and sustainability. International Review of Research in Open and Distance Learning, 10(5), 1-13.

Guri-Rosenblit, S. (1999). Distance and campus universities: Tensions and interactions. Oxford, UK: IAU Press.

Hylén, J . (2006), Open educational resources: Opportunities and challenges. Available at: http:// www.oecd.org/ dataoecd/5/47/37351085.pdf

Iqbal, S., \& Qureshi, I. A. (2012). M-Learning adoption: A perspective from a developing country. International Review of Research in Open and Distance Learning, 13(3), 147-164.

Ivankova, N. V. \& Stick, S. L. (2007). Students's persistence in a distributed doctoral program in educational leadership in higher education. Research in Higher Education, 48(1), 93-135.

J ohnstone, S. (2005). Open educational resources serve the world. Educause Quarterly, 3, 15-18.

Kanwar, A. Balasubramanian, K., \&Umar, A. (2010). Toward sustainable open education resources: A perspective from the Global South. American J ournal of Distance Education, 24(2), 65-80.

Kazis, R. (2007). Adult learners in higher education: Barriers to success and strategies to improve results. Washington, D.C.: U.S. Dept. of Labor, Employment and Training Administration, Office of Policy Development and Research.

Kiraz, E. \& Ozdemir, D. (2006). The relationship between educational ideologies and technology acceptance in preservice teachers. Educational Technology \& Society, 9(2), 152-165.

Knapper, C. \& Cropley, A. J . (2000). Lifelong learning in higher education. London: Kogan Page.

Kwon, H. S. \& Chidambaram, L. (2000). A test of technology acceptance model : the case of cellular telephone adoption. Proceedings of the 33rd Hawaii International Conference on System Sciences, pp. 1-10.

Liao, H. L., \& Liu, S. H. (2011). The effect of course, system and perception antecedents on adult learners' behavior. Issues in Information Systems, 12(2), 223-230.

Moeser, G., Moryson, H., Schwenk, G. (2013). Determinants of online social business network usage behavior-applying the technology acceptance model and its extensions. Psychology, 4(4), 433-437.

Moon, J . \& Kim, Y. (2001). Extending the TAM for world-wide-web context. Information and Management, 38(4), 217-230.

This work is licensed under a $\underline{\text { Creative Commons Attribution } 4.0 \text { International License. }}$ 
Moore, M. G., \& Kearsley, G. (2005). Distance education: A systems view (2nd ed.). Belmont, CA: Wadsworth Publishing Co.

Muilenburg, L. Y., \& Berge, Z. L. (2005). Student barriers to online learning: A factor analytic study. Distance Education, 26(1), 29-48.

Nistor, N., \& Neubauer, K. (2010). From participation to dropout: Quantitative participation patterns in online university courses. Computers \& Education, 55(2), 663- 672.

OECD (2007). Giving knowledge for free: The emergence of open educational resources. Report by OECE's Center for Educational Research and Innovation.

Oppenheimer, T. (2003). The flickering mind: The false promise of technology in the classroom and how learning can be saved. NY: Random House.

Park, S. Y. (2009). An analysis of the technology acceptance model in understanding university students' behavioral intention to use e-learning. Educational Technology \& Society, 12(3), 150-162.

Pantano, E., \& Pietro, L. D. (2012). Understanding consumer's acceptance of technology-based innovations in retailing. J ournal of Technology Management \& Innovation, 7(4), 1-19.

Rovai, A. (2003). In search of higher persistence rates in distance education online programs. Internet and Higher Education, 6(1), 1-16.

Stone, R. W. \& Henry, J . W. (2003). The roles of computer self-efficacy and outcome expectancy in influencing the computer end-user's organizational commitment. J ournal of End User Computing, 15(1), 38-53.

Thompson, R. L., Higgins, C. A., \& Howell, J . M. (1991). Personal computing: Toward a conceptual model of utilization. MIS Quarterly, 15(1), 124-143.

Venkatesh, V., Morris, M. G., Davis, F. D., \&Davis, G. B. (2003). User acceptance of information technology: Toward a unified view. MIS Quarterly, 27(3), 425-478.

Wiley, D. (2007). On the sustainability of open educational resource initiatives in higher education. Paper commissioned by the OECD at Center for Educational Research and Innovation (CERI) for the project on Open Educational Resources. Available at http:// www.oecd.org/ edu/ oer

Wood, C. (2005). Highschool.com. Edutopia Magazine, April/May, 32-37. 
Yildirim, S. (2000). Effects of an educational computing course on preservice and inservice teachers: A discussion and analysis of attitudes and use. J ournal of Research on Computing in Education, 32(4), 479-495.

(C) Kim, Lee, Lee, and Shon

\section{Athabasca University}

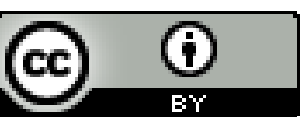

